Poznań Studies in Contemporary Linguistics 54(2), 2018, pp. 185-221

(C) Faculty of English, Adam Mickiewicz University, Poznań, Poland

doi: 10.1515/psicl-2018-0008

\title{
A MULTIMODAL APPROACH \\ TO THE ANALYSIS OF GENDER STEREOTYPES IN CONTEMPORARY BRITISH TV COMMERCIALS: "WOMEN AND MEN AT WORK"
}

\author{
MilagRos Del SAZ RUBio \\ Universitat Politècnica de València \\ masaru@idm.upv.es
}

\begin{abstract}
The aim of this article is to examine the meaning potential of images in the enactment or creation of gender stereotypes in a corpus of contemporary British TV commercials. The dimensions outlined in Goffman (1979) and some aspects of Kress and van Leeuwen's $(1996,2006)$ metafunctions are taken as a starting point to quantitatively and qualitatively analyse a sample of 155 ads which depict women and men in working settings. Findings indicate that women are mainly portrayed in non-remunerated scenarios, in home settings and in the company of their children. This view is reinforced thanks to the multimodal dimensions of framing (mostly through close-ups), involvement with other participants through looks, smiling and profuse touching activity. Men, in contrast, are mostly depicted in remunerated scenarios in which they address the audience directly through demand looks, acting as experts in their professional capacity and framed with medium and long shots. When portrayed together in non-remunerated activities, men are found in family scenes, although they are sometimes portrayed as passive subjects and mere objects of contemplation through lack of interaction with children or spouses. This contrasts with women's more communal role as they are intimately depicted in the company of their children through close-ups, feminine touch, and constant interaction with them. Stereotyped portrayals are less visually patent when both men and women are simultaneously depicted in remunerated scenarios, although some ads emphasize women's interpersonal skills as better at talking to customers or patients, whereas men are shown in the role of experts in financial and medical issues.
\end{abstract}

KEYWORDS: Multimodal analysis; semiotic resources; British TV ads; stereotyped portrayals; gender portrayals.

\section{Introduction}

When looking at the influence of TV commercials, we have to bear in mind the power of media discourses in reproducing and reflecting social, cultural and 
even economic changes. As Leitner (2001: 188) states, mass media outlets constitute social institutions through which media discourses transmit the ideologies of the members in those institutions. TV ads, as part of such media discourses, are seen by large swathes of the population day after day. ${ }^{1}$ Just to give an example, an average American child was reported to see 20,000 30-second TV commercials a year and to spend more time watching TV than doing any other activity except sleep in the 80s and 90s (cf. Dietz 1998; Dorr 1986). According to the report of the APA Task Force's committee on Advertising and Children (Kunkel et al. 2004), this exposure increased to 40,000 15-30 second TV ads at the beginning of the 21 st century. In a similar vein, Feierabend and Klingler (2011) reported that German children watched advertisements for $9 \%$ of their total TV viewing time, whereas British kids have been reported to spend 2.1 hours watching television per day according to the Childwise latest Monitor Report (2016). However, and in spite of the already existing stunning statistics, we, as viewers, are hardly aware of how ads affect us. There is even a sector of the population who truly thinks TV ads have practically no influence on them, and as spectators, we are even less aware of their role in processes of identity formation when exposed to them (Kilbourne 1999: 33).

In this respect, one of the most problematic areas of identity formation affecting young children is that of the identification of gender roles. Not in vain, issues of gender and sexuality lie at the core of how we perceive our identities (Gauntlett 2002; Jhally 2014), which have been thought to be greatly influenced by the mass media and, in particular, by advertising (Goffman 1979; Kim and Lowry 2005; Taylor et al. 2003). For a couple of decades now, gender has been best defined as being socially constructed (Brownell and Besnier 2013; Butler 1990), that is, "not part of one's essence, what one is, but an achievement, what one does" (Eckert and McConnell-Ginet 2003: 305). Despite the fact that we are born with a biological sex, gender is a social elaboration regardless of such physical differences; thus, we construct our own gender from the experiences we form through our socialization process and the roles we exhibit can be learned from a variety of sources including our families, friends, books, or movies. Thus, gender is viewed as a more relational and performative notion and, accordingly, the gender binary distinction of "male" and "female" has not only been questioned but currently disputed, and has given way to the progressive

\footnotetext{
${ }^{1}$ A recent online report in the BBC News Entertainment \& Acts, states that TV viewing time is underestimated, and that viewers of all ages watched an average of more than 28 hours a week in 2010 .
} 
recognition of other gender identities outside this binary under the umbrella term "transgender" (cf. Grossman et al. 2006). ${ }^{2}$

In spite of this, the mass media in general and TV ads, in particular, are major channels through which representations of the cultural system of gender binaries (male vs. female) are conveyed and reaffirmed (Patterson and Hogg 2004), as they explicitly or implicitly involve images of men and women who "naturally" engage in all type of relationships (cf. Bell and Milic 2002; Craig 1992; Furnham and Mak 1999; Ganahl et al., 2003; Lindner 2004). ${ }^{3}$ This makes the discourse of TV advertising a worthy area of investigation, especially for researchers with a critical agenda, as advertising constitutes a potential locus in which dominant and stereotyped representations of the sexes are likely to arise and this, in turn, reifies advertising's ability to guide gender role formation. ${ }^{4}$

Likewise, studies addressing the portrayal of gendered stereotypes in the media, and especially in TV ads, are pervasive. ${ }^{5}$ Some are comparative and of a longitudinal nature and have aimed to assess whether the roles of men and women have changed over time through content analysis or, on the contrary, have remained basically the same in similar or different cultures (cf. Acevedo et al. 2006; Allan and Coltraine 1996; Baker 2005; Bretl and Cantor 1998; Ferrante et al. 1988; Frith et al. 2004; Lovdal 1989; Mager and Helgeson 2010; McArthur and Resko 1975; O'Donell and O'Donell 1978; Paek et al. 2010; Signorelli et al. 1994). These studies have all agreed on the unequal or biased depiction of male and female characters in TV commercials (Tsichla and Zotos 2013): that is, men normally outnumber women in TV programming (Coltrane and Messieno 2000; Signorelli and Leavs 1992) women are unequally portrayed in TV commercials (Ferrante et al. 1988; Lovdal 1989), and are shown in the traditional or stereotyped roles of mothers and housewives (Courtney and Whipple 1983; Mager and Helgeson 2011; Tuchman 1978), while being placed

\footnotetext{
${ }^{2}$ A good indicator is Queer Studies and Queer Theory, which have been challenging such a dichotomy for a while.

${ }^{3}$ Although most studies in gender stereotyping on advertising tend to focus on the binary dichotomy of male/female, an interesting exception can be found in Rocha-Rodrigues (2016) whose research focuses on advertising campaigns which aim to deconstruct the gender identity and expression dichotomy.

${ }^{4}$ The effects children's exposure to stereotyped portrayals of men and women on TV ads can have on their gender role development and expression is not an aspect dealt with in this paper. However, this claim serves as a partial motivation for its critical agenda.

${ }^{5}$ See Rudy et al. (2010a, 2010b) for a thorough description of the most updated quantitative content analyses of gender roles in a wide variety of media, including TV advertising.
} 
in the home rather than in outdoor, public or business settings (Milner and Collins 2000; Shrikhande 2003; Valls-Fernández and Martinez-Vincente 2007) or placed in decorative roles (Plakoyiannaki and Zotos 2009) and as low-income earners (Belkaoui and Belkaoui 1976). For instance, even though women tend to be represented as working outside the home in prime-time television, their occupations still remain stereotypical and traditional (i.e., they are quite often depicted as nurses, secretaries or teachers [cf. Kalisch and Kalisch 1984; McNeil 1975; Vande Berg and Streckfuss 1992]). Women are also normally younger than men (Milner and Higgs 2004) and overrepresented in cosmetic and beauty products (Nassif and Gunther 2008). Carter and Steiner (2004) have also criticized the distinct and stereotyped representation of men and women regarding psychological and physiological features (i.e., women are emotional and weak while men are competent and strong), and the fields of action in which they are found (the household and family in the case of women, and paid working environments, sports and technology in the case of men). Such stereotyped gender representations in the media can certainly influence how society perceives gender roles as well as their attitudes and behaviors (cf. Geis et al. 1984; McKay and Covell 1997). Not in vain, several empirical studies have shown that exposure to gender-stereotyped media contents helps reinforce stereotypical perceptions, attitudes, and behavior (Lovdal 1989), as well as affect socialization, and the gender identity development of young people (Subrahmanyam and Smahel 2011; Zarghooni 2007).

In order to approach the analysis of stereotypical depictions of women and men in TV ads in a rigorous way, it is important to accept that research has already gone beyond what is verbally conveyed in TV ads or programs. In this respect, the last few decades have seen so much mixture of modes, especially the visualization of communication, that multimodality has become an important factor in discourse studies (Machin 2007, 2010; Machin and Myer 2012; Renkema 2004). Thus, the use of multimodal semiotic resources such as color, ${ }^{6}$ music, gestures, or framing is common in gender analysis. Recent research has also approached the analysis of gender, language and discourse from a critical multimodal perspective, as evidenced by the special issue on Gender and Modality published in 2016 in the journal Gender and Language.

Taking all the above mentioned into account, the aim of this article is to assess the existence of gender stereotyping in a corpus of contemporary British

\footnotetext{
${ }^{6}$ For a study on the role color plays in gender stereotyping in online health-messages see Yang and Lee (2016).
} 
TV commercials. In order to achieve this aim, images, as semiotic resources, constitute the focus of the analysis. Thus, the meaning potential that advertising images may have for the creation and reproduction of gender stereotypes will be looked into through the careful analysis of some of the semiotic dimensions developed in Goffman's Gender Advertisements (1979) and Kress and van Leeuwen's visual grammar (2006). In this respect, the nature of such gender portrayals will determine whether they rely on stereotypical and traditional depictions of men and women, as evidenced by previous research content studies (cf. Coltrane and Adams 1997; Heilman 1983; 1995 and 2001), or whether they reveal more inclusive gender representations.

The Multimodal Analysis of TV Ads Corpus (henceforth MATVA) has been employed for this purpose and 155 British TV ads which depict women and men as actually "working" in both remunerated and non-remunerated scenarios have been analyzed. The motivation for this choice of TV ads stems from the fact that - to my knowledge - no other study has focused on TV ads which portray working scenarios, except for DeFleur's (1964: 65) pioneering study, in which she concluded that the world of work in television was a man's world. What is more, the workplace is an area especially prone to the enactment of gender portrayals. Likewise, gender stereotyping has been well investigated in prime-time TV, whereas off-peak advertising has received less attention.

Bearing in mind previous research on gender stereotypes, and considering the progressive incorporation of women into the workforce in developed countries and their colonization of traditionally male arenas - together with the progressive contribution of men to domestic chores and children's education, this study will also shed light on whether contemporary advertising practices keep pace with these changes. In this respect, this study provides a more updated extension of previous work on gender stereotypes and falls within a critical- multimodal framework of analysis (cf. Fairclough 2003; Wodak 2001; Wodak and Weiss 2003), as it is ultimately my aim to unveil advertising trends and ideological differences regarding the representation of women and men in working and/or domestic settings.

The remainder of this article will be organized as follows. First of all, the main tenets which make up the analytical tools employed in this study will be outlined. Next, the methodology will be presented, followed by a description of the corpus of study. Then, a results and discussion section is provided where the results of the quantitative and qualitative analysis are presented and discussed. Finally, there is a section devoted to conclusions and further research. 


\section{Theoretical framework}

When approaching the analysis of TV commercials, the combination of language and visuals has long been the norm in an attempt to create the maximum impact to persuade the audience. In fact, the established supremacy of the verbal mode in advertising has slowly given way to visual images as an integral semiotic mode of texts production and interpretation (cf. Hyland 2009). As a result of the fact that discourses have become more and more multimodal, current analyses of TV ads have made an effort to account for various semiotic modes in order to access the intended meanings of advertisers (cf. Pennock-Speck and Del Saz-Rubio 2013). Thus, aspects of visual design in TV ads, including the uses of color, and images are combined and integrated with the spoken language of the represented characters (alongside aspects such as intonation, voice quality or gesture), with the linguistic messages conveyed by the voice-overs, together with the typography of superimposed written language on the screen and the auditory mode (whether diegetic and non-diegetic) which accompanies the ad to create a semiotic whole. However, this does not mean that the independent analysis of each of the modes should be discarded; on the contrary, focusing attention on one of these modes can help us understand how it contributes to the meaning of the semiotic whole. Research within the Systemic Functional Linguistics framework has emphasized the intersemiotic complementarity between the visual-verbal modes in the field of advertising (Royce 1998, 2007). While I certainly agree with the view that it is impossible to disassociate the image from the text, as it is in their blending that they become a communicative act (Cook 2001; van Leeuwen 2004), I also agree with van Leeuwen (2008: 137) when he states that "if images seem just to allude to things and never "say them explicitly' we need to make these allusions explicit".

In this vein, the aim of this paper is to look into the meaning potential of images in a sample of British TV ads. Thus, Erving Goffman's dimensions - as outlined in Gender advertisements (1976) will be first studied. Next, I will revise the semiotic categories identified by Gunther Kress and Theo van Leeuwen (hence K\&vL) $(1996,2006)$ for the analysis of images. The decision to combine some of the variables employed in both approaches lies in their extensive and successful application in content analysis of gender stereotypes, especially Goffman's study (cf. Belknap and Leonard 1990; Bell and Milic 2002; Busby and Leichty 1993; Kang 1997; Klassen et al. 1993; Sirakaya and Sönmez 2000; Umiker-Sebeok 1996) in print advertising or in social media platforms (cf. Döring and Pöschl 2016). For its part, K\&vL's grammar approach to visual communication constitutes, up to now, the only descriptive framework of multimo- 
dality which allows the researcher to analyze the potential meanings encoded by images, or as Machin (2007: xi) puts it:

Just as linguistics offers a more or less precise, systematic methodology for describing and analyzing language, so, drawing on this model, Kress and van Leeuwen have claimed to offer the same for the visual mode, for describing and analyzing visual communication. This would equip us with greater powers to describe what we see rather than referring to the effects of visual elements.

\subsection{Goffman's Gender advertisements}

Goffman's theoretical underpinnings provide clues to how gender roles are enacted in printed ads by focusing attention on subtle signs of behavior such as men and women's use of hands, eyes, their body positioning, facial expressions, gaze aversion and relative sizes, all of which represented the "subordination of women" and their infantilization. Goffman's study revealed that advertisements reflected an unequal relationship between men and women. Goffman's dimensions are summarized below:

(1) Relative size: Goffman states that one way in which power and superiority can be indexed is through relative size or height. That is, "the male's usual superiority of status over the female will be expressible in his greater girth and height" (Goffman 1979: 25). ${ }^{7}$ He found that women were depicted as smaller, or lower than men in his sample.

(2) The feminine touch: the way that women, more often than men, tend to be pictured lightly touching or ritually caressing objects (or themselves) in advertisements, whereas men are depicted more often as grasping, manipulating or holding objects.

(3) Function-ranking: this category aims to reveal what men and women do when portrayed in a collaborative activity: males are usually presented in the role of executors, while females act as secondary or supporting characters. What is more, Goffman showed that the tasks in which women were engaged, tended to be of less import that those performed by male participants.

\footnotetext{
${ }^{7}$ Goffman's dimension of relative size will not be looked into as previous experience in the analysis of TV ads indicates that there is no significant difference regarding the size of male and female characters in TV ads (cf. Bell and Milic, 2002; Döring and Pöschl, 2016; Kang, 1997).
} 
(4) The family: that is, the portrayal of family members and their organization, which provides clues to this institution's social structure. Goffman noticed the effort to exhibit the "presumed special bond between the girl and the mother and the boy and the father". (Goffman 1979: 37).

(5) Ritualization of subordination: subordination to others involves the physical lowering of oneself to others, lying on surfaces (floor or bed) when inappropriate, body and/or head canting postures, puckish smiles, or the use of the body "as a playful gesticulative device" (Goffman 1979: 50) and the "arm lock" as a tie-sign in Western societies signaling the protection of women by men.

(6) Licensed withdrawal: this category refers to characters, mainly women, being removed (either physically and/or mentally) from a particular situation, thus reinforcing their helplessness and dependency on other characters, presumably male.

\subsection{Kress and van Leeuwen's Visual Social Semiotics}

K\&vL $(1996,2006)$ in their aim to move away from a monomodal approach to discourse, developed a tool kit to approach the analysis of visual representations or arrangements, which they defined as a grammar approach to visual communication drawing on the three meta-functions developed in Halliday's account (2004). As social semioticians, K\&vL assigned a representational, interpersonal and compositional/textual meaning to images.

The representational metafunction deals with the twofold ability of images to represent aspects of the world as narrative or conceptual. Narrative representations show some form of action, especially in the case of the so-called reactional processes, in which vectors are formed by an eyeline, by the direction of the glance of one or more of the represented participants. By looking at reactional processes some insight into how gender roles are distributed in both remunerated and non-remunerated working scenarios will be gained in order to assess, among other things, whether " [...] when a man and a woman collaborate in an undertaking, the man is likely to perform the executive role" (Goffman 1976: 32), or simply to determine what type of actions women and men perform in the sample analyzed.

For its part, the interactive or interpersonal metafunction is concerned with three categories which illustrate how what is represented in a visual composition interacts with the viewer and/or aligns him/her with the participants through (i) gaze, (ii) frame and social distance, and (iii) angle of interaction. 
Gaze deals with the way interaction is established between the represented participants of the ad and the viewer. Thus, images can either establish a direct contact with viewers through what they call a demand gaze, in which represented participants directly gaze at the viewer, or through an offer gaze in which participants do not acknowledge the viewer by avoiding direct contact with the $\mathrm{him} / \mathrm{her}$. In the former case, viewers are addressed explicitly with a visual 'you', whereas in the latter, the represented participants are items of information waiting to be scrutinized by the viewer.

Size of frame and social distance refer to the choice between close-ups, and medium and long shots to portray represented participants and objects in images. Goffman's postulates are based on Hall's (1966) work on the notion of "proxemics". Thus, the distances we keep among intimates ("close personal distance") differ from those we keep when we are among strangers ("far personal distance"). Likewise, through angle of interaction or "perspective" (K\&vL 2006: 129) images suggest relations of involvement (horizontal angles) or power (vertical angles). Finally, layout or composition shows that the arrangement of visual signs is a well-considered choice that helps reinforce the way societies and institutions are organized (cf. Iedema 2003, Jewitt and Oyama 2001). ${ }^{8}$

3. Corpus and methodology of analysis: The multimodal analysis of TV ads

\subsection{Corpus description: The "Women and Men at work" corpus}

The aim of this paper is to investigate stereotyped portrayals in ads that depict women and men performing "work of any kind". To this end, I have used the MATVA corpus, which is made up of four days of British TV ads recorded from the British TV channels ITV and Channel 4 during 2009, 2010 and 2011 within the non-prime time slot, just before peak-time viewing begins in the UK. Although there is an extensive body of gender research on prime-time television, several authors have stated that women and men have an equal presence in advertisements during daytime (cf. Culley and Bennett 1976-USA; Downs and Harrison 1985-USA), an aspect worth investigating.

The corpus consists of 1,285 ads, and it contains the transcription of spoken and written discourse, on the one hand, and a description of the various dimen-

\footnotetext{
${ }^{8}$ Due to time, corpus length and space limitations, K\&vL's category of angle of interaction (interpersonal function) and their textual metafunction will not be assessed for the purpose of this paper.
} 
sions of para- and extra- linguistic elements of all the non-duplicated ads. ${ }^{9}$ After the corpus was collected, duplicated ads, institutional advertisements, advertisements with no adult human characters (animated on-screen characters or cartoons) and movie promotions were discarded, as the aim was to compile examples of commercial consumer advertising (Leech 1966). The total number of non-duplicated ads obtained was 621 . After that, only those ads in which a man, a woman, or both a man and women were jointly portrayed as doing work of any kind were selected for analysis. Work has been divided into remunerated work, for ads featuring professional settings such as an office, a building site or a context in which it could be construed that remunerated work is taking place (for example, a post-office worker delivering letters or packages) and nonremunerated work, which refers to any activity in which people are engaged in household chores, shopping or looking after children.

\subsection{Methodology of analysis}

In order to handle the multimodal description of the "women and men at work" corpus and be able to assess the different dimensions and categories selected for analysis and thus unveil the meaning potential of images, I will first sequence each of the ads which make up the corpus into still images or shots using the VLC Media Player application for the extraction of video frames. Each ad will be then transcribed and analysed in a phase fashion based on Baldry and Thibault's transcription toolkit (2006), although simplified and operationalized to suit the aims of the current paper (cf. Pennock-Speck and Del Saz-Rubio 2013, for a similar insight). In other words, I will not provide such detailed analyses as the ones encountered in the templates of previous researchers dealing with multimodal text transcription (cf. Thibault 2000; Iedema 2001; Baldry 2004 and O'Halloran 2004, to name but a few) because such analyses go beyond the scope of this article by aiming to describe the contribution of every potential meaning-making mode (for example, gesture, music, gaze, and clothing) in an endless row of columns and in extreme detail.

In the next step, the semiotic variables taken from Goffman and K\&vL will be assessed in each of the shots which make up ads in the corpus. Goffman's variables, as explained in Section 2.1, will be analyzed except for relative size.

\footnotetext{
${ }^{9}$ The MATVA corpus has been employed as a reliable corpus sample in previous research carried out by Pennock-Speck and Del Saz-Rubio (2013) and by Pennock-Speck and Fuster-Marquez (2014).
} 
Ritualization of subordination subsumes the category of smile, together with head canting and lying on surfaces. Regarding K\&vL's metafunctions, the ideational one can be best subsumed within two of Goffman's six behavior groupings: function ranking and feminine touch. Under K\&vL's aspects of interpersonal function, I will assess the way that the represented participants look at each other in the TV ads and whether they directly address the audience (demand gaze), or are presented as objects of contemplation (offer gaze). Goffman's dimension of licensed withdrawal ("undirected gaze") will be subsumed in the broader category of gaze as one type of offer gaze. Gender framing will look into how social distances are managed to assess whether the participants are depicted through close-up shots (intimately), medium (social distance) or long shots (public distance) (Bell 2001). Body parts will also be accounted for as part of this dimension as their use presupposes the objectification of the represented participants through close-ups of body parts. Finally, I will also consider the following dimensions: the gender of the voice-over (either male or female) in order to elucidate who holds the voice of authority and the product type, i.e., domestic or non-domestic. ${ }^{10}$

Such dimensions will be both quantitatively and qualitatively described. Quantitative analyses are essential in approaching the analysis of any large corpus of TV ads as they yield first-hand measurable and objective information on the data under analysis. In this respect, the results obtained for the specific semiotic resources or dimensions tested here are based on counts, as I have recorded frequencies of appearance for each dimension in all the different gender categories and scenarios contemplated. A qualitative analysis will also be carried out as key in contextualizing the raw numerical data provided by the quantitative analysis. For example, while the quantitative analysis may simply indicate that both men and women are portrayed in a similar percentage when in the company of their children in non-remunerated scenarios, the descriptive analysis will help unveil certain subtleties, such as what type of activities are carried out with the children (tending them, playing with them, or feeding them, for example), and who does what. Thus, a qualitative or descriptive analysis will be key in explaining and unmasking certain stereotypical depictions which the raw numerical data cannot explain and most certainly will obviate.

\footnotetext{
${ }^{10}$ I follow Lovdal's (1989: 179) definition for "domestic" products as "[...] items used in the home such as food, cleansing products, cosmetics and home remedies".
} 


\section{Results and discussion}

First, the general percentages obtained for each of the semiotic dimensions under analysis will be provided. Then, a more detailed presentation of the results will be made for each gender category (female, male and both female and male together) and scenario type (remunerated and non-remunerated). ${ }^{11}$

$25.3 \%$ of the TV ads (155) in the MATVA corpus featured work performed by the gender categories, whereas $74.7 \%$ were found to feature no working activity of any kind. Ads featuring remunerated work represent $60 \%$ of the commercials ( 93 ads), whereas $40 \%$ of the ads in the corpus display nonremunerated working scenarios (62 ads).

Figure 1 illustrates the distribution of the gender categories of women, men and women and men together in working scenarios.

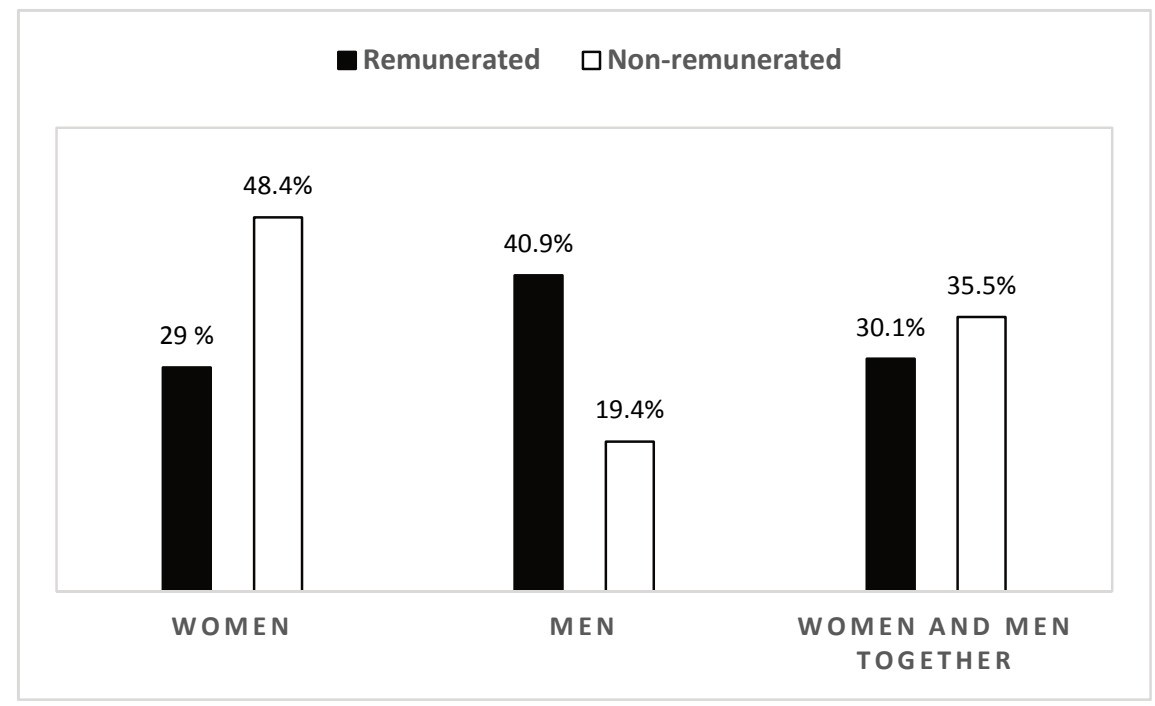

Figure 1. Gender distribution in remunerated and non-remunerated scenarios.

\footnotetext{
${ }^{11}$ Due to space constraints, a detailed analysis of all the variables selected for analysis for each of the scenario types and gender categories cannot be provided. Therefore, for each gender and scenario type, only those dimensions which have proved to be more relevant for the enactment of stereotypical views of women and men will be highlighted.
} 
The highest percentages obtained correspond to women in non-remunerated jobs $(48.4 \%)$ and men depicted in remunerated scenarios (40.9\%), followed by $35.5 \%$ of the ads which depict both men and women together in nonremunerated activities. In contrast, the lowest percentages account for men in non-remunerated settings (19.4\%), followed by women portrayed in remunerated settings (29\%), and both men and women together in working scenarios with a similar percentage of occurrence (30.1\%). These findings coincide with Knoll et al.'s (2011) study on gender stereotyping in public vs private German TV channels, in which they found that gender stereotyping was pervasive regarding occupational status.

Findings indicate that male and female voices are employed in similar percentages to round up the commercials ( $48.3 \%$ vs $51.7 \%)$. However, $69.7 \%$ of the ads have a female voice to advertise domestic commodities, whereas male voice-overs are only employed in $30.3 \%$ of the ads for the same product type. Male voice-overs are preferred for non-domestic products (64.1\%), while female voices are clearly underrepresented in this category (35.9\%).

As far as function ranking is concerned, results in this sample indicate that main participants in the ads are portrayed as working in $95.8 \%$ of the cases. Only $4.2 \%$ of the ads includes either women or men portrayed in what could be considered a passive role ${ }^{12}$ and only in non-remunerated scenarios.

With regards to the family variable, $28.4 \%$ of the ads depict either women, men or both together in the company of their children in non-remunerated scenarios. The frequency of appearance is higher (95.2\%) in the company of both men and women. Children (mostly girls and boys together) are portrayed in the company of their mothers alone in $64.3 \%$ of the ads, and depictions with the male-father figure account for $33.3 \%$ of the ads in the sample.

If we look at the way the participants engage interpersonally with other represented participants and/or the audience, women engage more often with other characters in the ads than their male counterparts $(61.4 \%$ versus $38.6 \%$, respectively). Offer-looks are employed with similar frequencies for men and women (49.4\% for male and $50.6 \%$ for female characters). Demand looks only appear in $10 \%$ of the ads and women address the audience directly less than their male counterparts (36\% versus $64 \%)$. Feminine touch is present in $21 \%$ of the ads and is more pervasively employed in non-remunerated scenarios $(54.8 \%)$ than in remunerated ones $(45.2 \%)$, as an exclusive category for female participants.

\footnotetext{
${ }^{12}$ For "passive" portrayals I mean ads where women or men are not engaged in any obvious activity which may be construed as "work". For example, a policeman is depicted but with no active role in the ad, so that we can only attribute him the role of policeman because of his outfit rather than because he's really fulfilling such an occupation.
} 
Body parts are present in $17 \%$ of the ads, with women's female body parts being more frequently employed to advertise products in the corpus than those of their male counterparts ( $78.4 \%$ versus $21.6 \%$ ).

With regards to the semiotic resource of gender framing, women are found to be portrayed more intimately than their male counterparts $(37.5 \%$ versus $22.5 \%)$ in general. Men, in contrast, score higher frequencies for social $(27.4 \%$ versus $21.9 \%$ ) and public distances (50\% versus $40.6 \%)$.

As for the category of ritualization of subordination, the smile is the most pervasive resource employed for women $(62.1 \%$ vs $6.8 \%$ for men). Head canting $(12.9 \%)$ and lying on surfaces $(12.1 \%)$ are variables which only apply to female characters.

\subsection{Women and men in non-remunerated jobs}

Women in non-remunerated situations are present in $48 \%$ of the ads in the traditional roles of mothers who look after babies or teenagers (i.e. Bepanthen, Aptamil, Sudocream, and Pampers), or provide them with food (as in Nutella, Kellogg's Pops and Dairylea Dunkers). Women are also in charge of domestic cleaning chores (for example in Dettol All in One, Vanish Carpets, Twist a mop, or Mr Muscle). Products are exclusively of a domestic nature (cf. Knoll et al.'s (2011) study in which they reported that women were, indeed, more likely to be depicted with domestic products than men).

Regarding function ranking, female characters are depicted as extremely active mostly within the home $(72.6 \%)^{13}$ and in the company of their children $(64.3 \%)$, hence reinforcing their role as caregivers and natural nurturers. This ties in well with research carried out by Emons et al. (2010) and Koeman et al. (2007) who found that women were more likely to be cast in nurturing or marital roles on TV.

With regards to gaze type, female characters do not gaze at the audience directly and are outstandingly portrayed interacting with other represented participants (kids or husbands, or product experts) in $53.7 \%$ of the ads analyzed (i.e. Bepanthen, Aptamil Follow On, Rias, Cillit Bang and Mr Muscle), as shown in the frames in Figures 2-5 below.

\footnotetext{
${ }^{13}$ This finding coincides with O'Donnell and O'Donnell's study in which women were found to be domestic product representatives in the home setting in $76 \%$ of the commercials. What is more, the majority of these ads depicted women selling products in the bathroom and/or the kitchen (Busby 1975; Courtney and Whipple 1974; Dominick and Rauch 1972).
} 


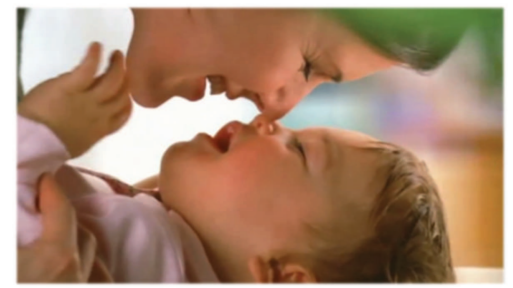

Figure 2. Bepanthen.

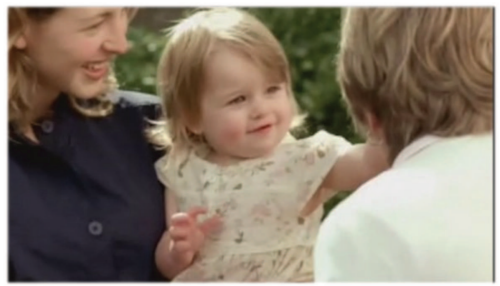

Figure 3. Pampers.

(Colour online.)

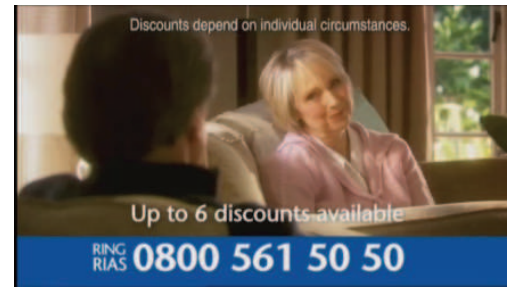

Figure 4. Rias.

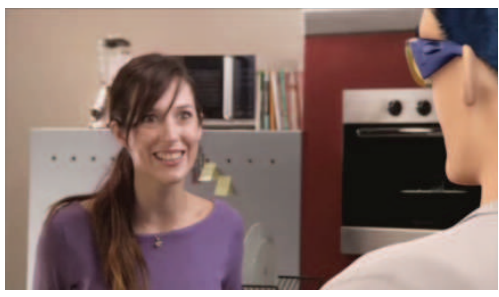

Figure 5. Mr. Muscle.

(Colour online.)

When interacting with children, women are intimately framed through close-ups in $78 \%$ of the ads, whereas male characters are intimately portrayed in just $22 \%$ of the cases. They also touch their children profusely (feminine touch) (77\%) and nuzzle their babies' noses (27\%), hence highlighting the emotional tie between mothers and children as part of their being warm and caring (cf. Burgess 1999). Other resources reinforcing the view of women as caregivers are that of smiling back to their children $(89.7 \%)$ and the lying on surfaces $(42.8 \%)$, as shown in Figures 6 and 7 in the Aptamil and Vanish Clean ads.

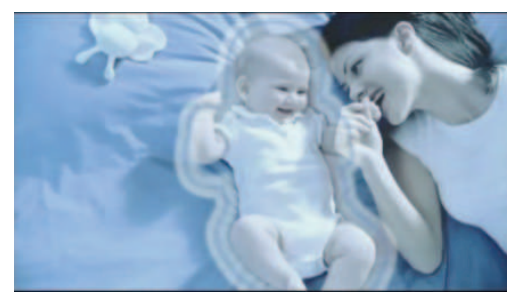

Figure 6. Aptamil.

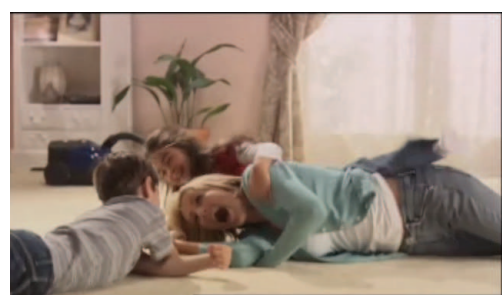

Figure 7. Vanish Clean.

(Colour online.) 
Interaction with other participants beyond children is restricted to "expert male characters" who provide a solution to the women's problems and come to their rescue (for example in Mr. Muscle or the Cillit Bang ads). Such ads rely on the traditional stereotype of women as needing the help or protection, and the guidance of a male character who has more active or instrumental characteristics (cf. Parson and Bales 1955; Carli 1990 for similar insights) as they are instructive, directive, pass judgement on the products efficiency and come up with solutions to problems. Women, on the contrary, display a more passive or emotional behavior in their company as they smile, listen to men as authority figures and put their advice to practice by actively scrubbing stains and cleaning surfaces. The stereotype of the male character as more knowledgeable is doubly reinforced by the use of male voice-overs that do not only round up the ads but "talk science" and provide figures to back up the bits of information about products and their reliability (Oust 3 in one "... kills $99 \%$ of bacteria and viruses on hard surfaces").

When women do not react to other represented characters, they are best to be looked at as objects for contemplation through offer-looks (as exemplified in JML Doktor Power, JML Fresh Bags, or Twist a Mop). These ads portray women whose gaze is like a 'non-transactional reaction' in K\&vL's terms (1996: 74); thus, leaving the audience to muse over their most intimate and inner thoughts, together with the use of close-ups, smiles and head canting as shown in the shots from the Keep Fresh Bags ad in figures 8 and 9.
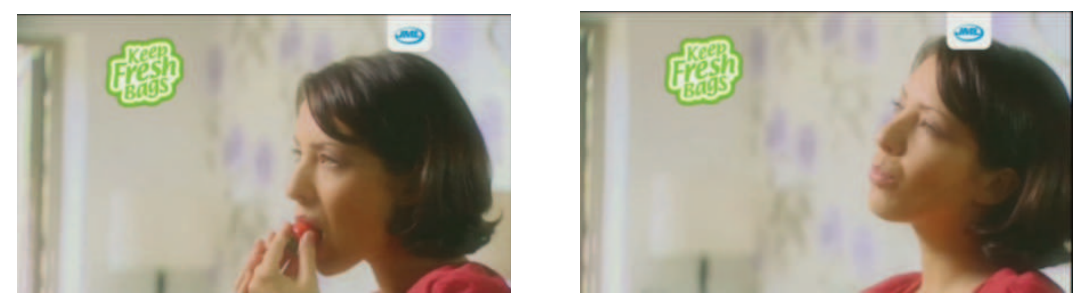

Figures 8-9. Keep Fresh Bags.

(Colour online.)

Body parts are employed in $53.6 \%$ of the ads. Women's hands scrub and clean surfaces, for example in the Dettol all in One or Cillit Bang ads shown in Figure 10. 


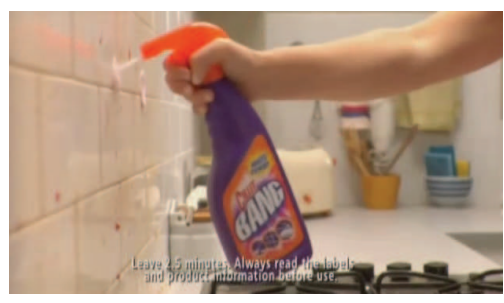

Figure 10.Cillit Bang Grime \& Lime. (Colour online.)

Half the ads in this category feature a male voice-over as the voice of authority to advertise not only cleaning products but also products outside the "domestic" range, for example in NHS Smokefree, Haven.com, and MacMillan Cancer Support charity. In contrast, female voice-overs are employed to advertise products for babies' hygiene and nourishment (i.e., Bepanthen, Sudocrem, Pampers, Aptamil, Coco Pops and Nutella), or cleaning products when in the company of their children (i.e., Vanish and Dettol all in One).

Men in non-remunerated situations represent $19.4 \%$ of the ads assessed and they are not depicted in domestic chores such as cleaning and baby tending. Men execute tasks (function ranking) related to the products advertised in the ads: for example, Chef Phil Vickery prepares a chocolate fondue (Aldi); male participants enumerate the fantastic offers for a family barbecue meal (Morrisons), vacuum clean carpets (Miele), paint the decking areas of the yard (Ronseal Paint), or do some gardening (Maltesers). ${ }^{14}$ They are also engaged in parenting activities within the home (57\%), mainly with teenagers (as in SMA formula milk, Piritize allergy tablets, or Haven.com) with whom they play.

Interaction with other represented characters is less common in this subcorpus $(14.6 \%)$, a fact that makes male characters come across as less prone to engaging interpersonally if compared to their female counterparts. Male characters in the company of their offspring are less frequently depicted than women ( $25 \%$ versus $64.3 \%$, respectively). Men play with teenager boys in outdoor locations (at the beach) (Haven.com), or in their yard (Piritize Allergy Tablets), and take them fishing in the canals (NHS Smoke free), as is illustrated in Figures 11 and 12 .

\footnotetext{
${ }^{14}$ The yard or the garden are stereotypical arenas for men to carry out domestic activities.
} 


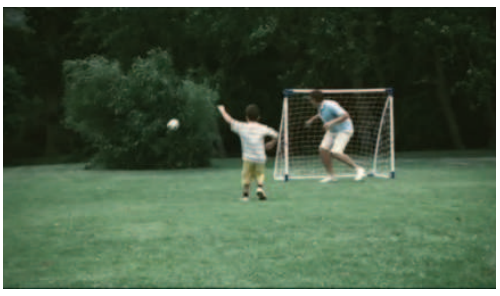

Figure 11. Haven.com.

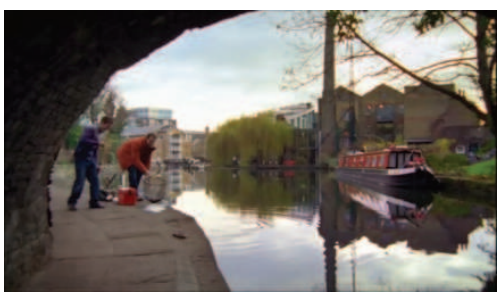

Figure 12. NHS Smoke Free.

(Colour online.)

Expert male characters address the audience directly through demand gazes in $25 \%$ of the ads analyzed to talk about the product properties. This is clearly emphasized in the Ronseal Paint, Aldi and Morrison Price Crunch ads. Men are framed through medium and close-shots to create intimacy with the audience as the shots in Figures 13 and 14 show.

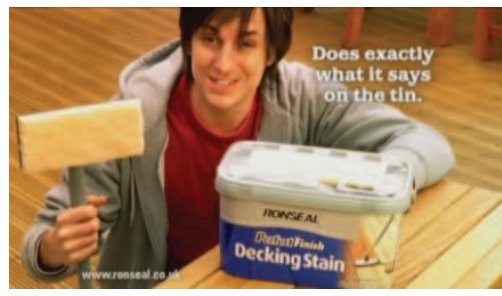

Figure 13. Ronseal Paint.

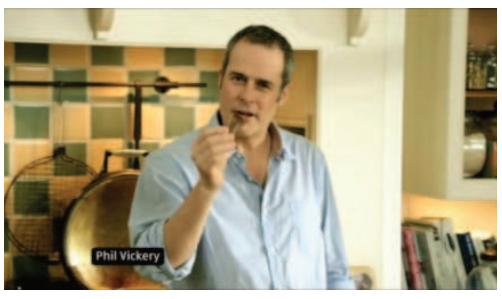

Figure 14. Aldi.

(Colour online.)

Notwithstanding, framing is mainly achieved through long and occasionally medium shots, except for some ads which alternate long, medium and close shots, hence framing male characters more intimately. For example, in the NHS Smoke Free ad, a dad is quite intimately portrayed to emphasize his smoking (see shot in Figure 15); in the Aldi ad the chef celebrity is intimately talking to us, followed by the SMA formula milk ad where the man is depicted holding his baby girl in a more intimate way (Figure 16). 


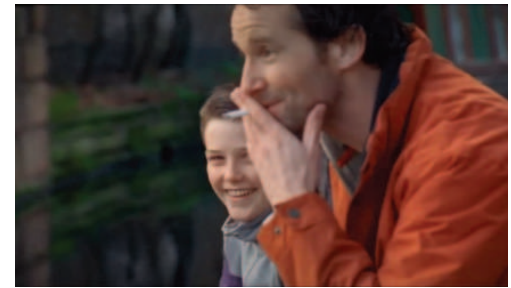

Figure 15. NHS Smoke Free.

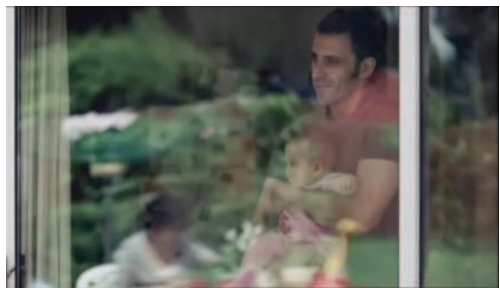

Figure 16. SMA Formula Milk.

(Colour online.)

$47.5 \%$ of the ads in the sample make use of a male voice-over (for example in Ronseal, Morrison Price Crunch and Piriteze), whereas 52.5\% of the commercials feature a female one in ads dealing with nurturing activities which involve the use of formula milk, (i.e., SMA formula milk), with cleaning tasks (Miele vacuum cleaner), or with furniture purchase decisions (i.e. Sharp Bedrooms).

\subsection{Both women and men together in non-remunerated scenarios}

Men and women in non-remunerated scenarios represent $35.5 \%$ of the ads analyzed and are depicted in their role as parents with a frequency of $90.5 \%$. The stereotypical family scene of the father, mother, daughter and son is present in $73 \%$ of the ads which include teenagers, a fact that indicates that this is still a pervasive stereotype in advertising (cf. Farris 2014).

The parenting activities portrayed range from having meals with children, either at home or outside (as in KFC family dinner, Pizza Hut, Thirst Pockets and Braces Bread), to spending holidays or leisure time together (i.e., $\mathrm{Ha}$ ven.com, Devon Holidays or Nivea Sun Spray). Men and women mostly interact with children $(62 \%)$ as a family. No demand looks have been found and offer looks which invite the contemplation of characters are found in $24 \%$ of the ads analyzed as shown in the shots in Figures 17 and 18.

Framing is enacted thanks to the alternation of medium and long shots as the norm. Intimate depictions are found in $36 \%$ of the ads analyzed and women are the ones more intimately framed through close-ups, as shown in Nivea's Children Sunspray and Blood.co.uk where they are presented in their role as mothers, as seen in Figures 19-20.

Ritualization of subordination is enacted through smiling poses as $59 \%$ of the women smile and $41 \%$ of the male characters do smile too, which 


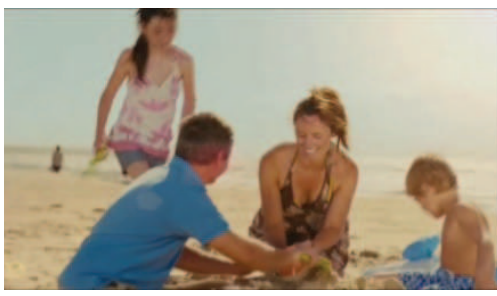

Figure 17. The Sun.

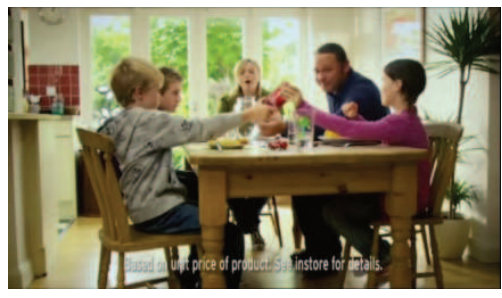

Figure 18. Sainsbury Ketchup.

(Colour online.)
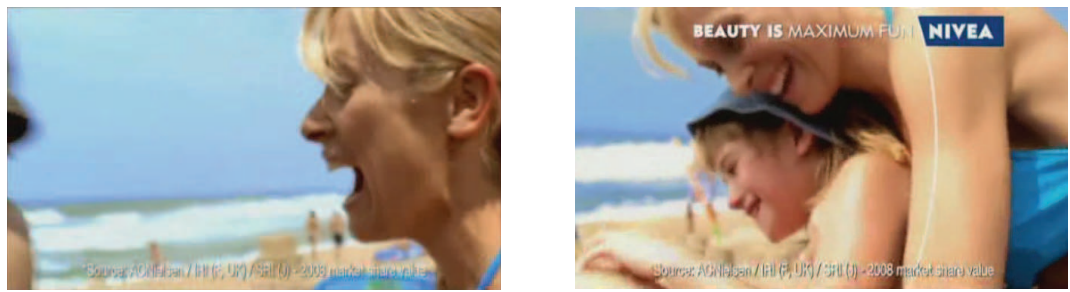

Figures 19-20. Nivea Sun Spray.

(Colour online.)

means that when portrayed in the company of women and children, men are more likely to smile.

Although both women and men are actively portrayed in the corpus, the main difference between this sub-group and the others lies in the quality of such portrayals. $72.7 \%$ of the ads in this category show male and female characters actively engaged in the shared activity of looking after their children. The remaining $27.3 \%$ include a male character who is neither actively depicted as a father, nor does he act like one (i.e. Harveys Furniture, KFC family dinner and Pizza Hut). In the Harveys Furntiture ad below, the father's passivity as a parent is emphasized through lack of interaction and eye-contact with his daughter or wife. This family scene reinforces the stereotype of women as caretakers and deploys a more detached, unemotional view of men as fathers, as illustrated in Figures 21-22.

These findings help reify what previous research has already suggested, i.e., that family life is has greater significance for women and that parental status is made more obvious for women than for men (Emons et al. 2010; Glascock 2001). 

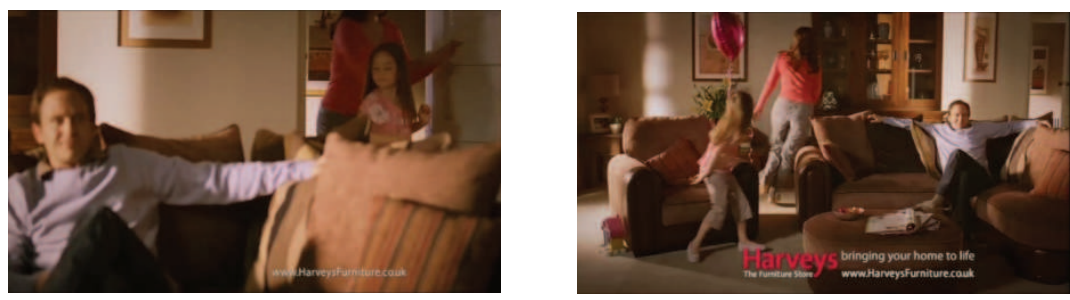

Figures 21-22. Harveys Furniture.

(Colour online.)
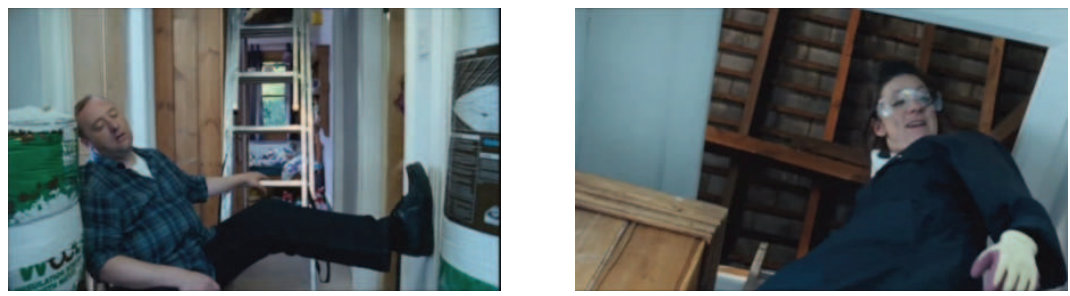

Figures 23-24. Act on C02.

(Colour online.)

In the Act on $\mathrm{CO} 2 \mathrm{ad}$, traditional gender roles have been reversed with the mother insulating the roof, a typically manly activity, while the father is just sitting on a chair. A comic effect is created by depicting a helpless man in a "manly' situation. This ties in well with the humorous portrayal of the "dumb father" stereotype as Bivins (2016: 65) states that: "in recent years, images of the manly man, hero, breadwinner, and outdoorsman have been displaced by images of men ass bumbling husbands and dumb dads", which is illustrated in Figures 2324.

\subsection{Women and men in remunerated scenarios}

Women represent $29 \%$ of the ads analysed and are mainly depicted in traditional jobs which range from blue collar occupations (supermarket cashiers, salespersons, beauticians, waitresses, yoga instructors) to more specialized jobs (airhostesses, teachers, physiotherapists, pianists, or gynaecologists). Products are primarily of a non-domestic nature $(67.8 \%)$. Demand looks are much more fre- 
quent than in non-remunerated scenarios ( $81 \%$ versus $19 \%)$ as shown in the Clear Blue Pregnancy Test, Lipobind, Pantene Pro-V or in the Ryvita minis ads, and women address the audience not so much because of their occupations, but, rather, as "product users". ${ }^{15}$ Women are intimately framed through close-ups and middle shots that help convey a nuance of intimacy and closeness with the audience, as can be seen in Figures 25 and 26.

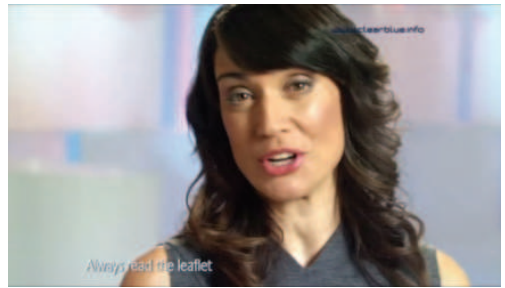

Figure 25. Clear Blue Pregnancy Test.

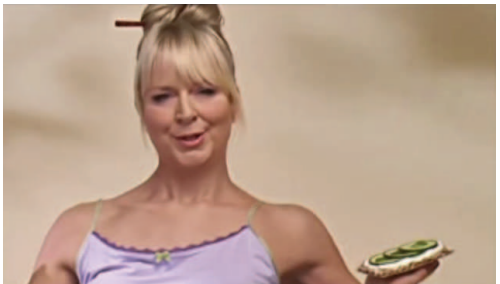

Figure 26. Ryvita minis.

(Colour online.)

The use of body parts is much lower than in non-remunerated scenarios ( 29.4 versus $44.1 \%$ ), although certainly higher if compared to the use men make of this resource in remunerated scenarios (5.9\%). Body parts mainly focus on hands that hold products (Somerfield and Clear Blue Pregnancy Test) or touch animals (The Dogs Trust). In the Pantene Pro-V ad, attention is drawn to the hands, feet, head and naked back of the woman, inviting us to gaze at her sexualized image (she adopts suggestive poses in her role of pianist through head canting), as in Figures 27-30.
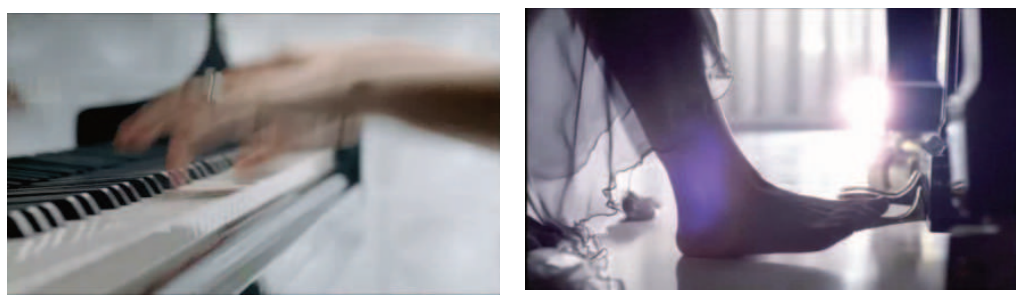

Figures 27-28. Pantene Pro-V body parts. (Colour online.)

\footnotetext{
${ }^{15}$ Twardowska and Olczyk (2003) found that women are rarely privileged to play the role of expert in Polish advertisements.
} 

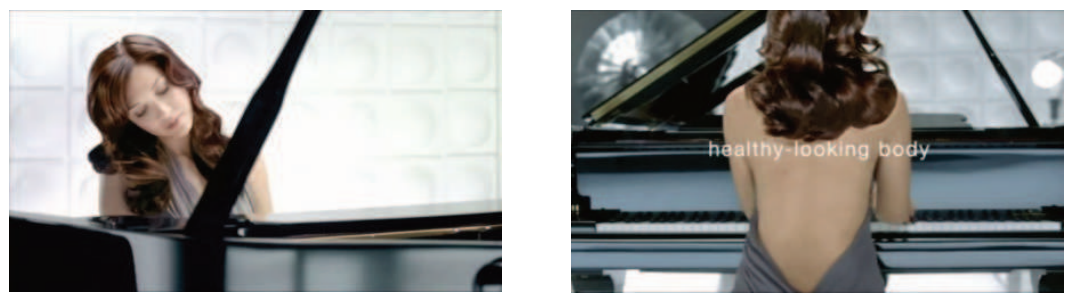

Figures 29-30. Pantene Pro-V body parts. (Colour online.)

As for the touching activity, percentages are quite similar if compared to nonremunerated scenarios ( $45.2 \%$ vs $54.8 \%$ ). The only notable difference is that the recipients of female touch in remunerated scenarios are either commodities or animals. Female participants touch, caress and nuzzle dogs, for example, in the same way that women are portrayed as touching and playing with their children in the non-remunerated category, as seen in Figure 31.

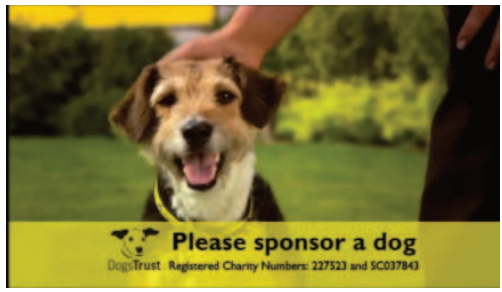

Figure 31. Sponsor a Dog. (Colour online.)

Ritualization of subordination is deployed through smiling poses in $85.7 \%$ of the ads analysed and female characters are framed through close-ups in $44.7 \%$ of the ads analysed, whereas male characters are depicted intimately in only $28.9 \%$ of the cases.

Men in remunerated scenarios represent $40.9 \%$ of the ads and the palette of occupations is clearly much wider than that of women (i.e., window panel and wooden floor installer, chauffeur, courier, petrol station worker, waiter, postman, social worker, clerk worker, dentist, male chef, Olympic sportsman, or lawyer).

Regarding gaze type, the percentage of men in remunerated scenarios who address the audience directly through demand looks is $46.5 \%$. Men endorse 
products and their expertise is brought about by their occupations as cooks or celebrity chefs (KFC, Kellogs Optivita), company experts in acid erosion (Sensodyne), lawyers (Harris Fowler), or expert chocolatiers (Lindt) (cf. Knoll et al. [2011] for similar insights), as illustrated by Figures 32-33.

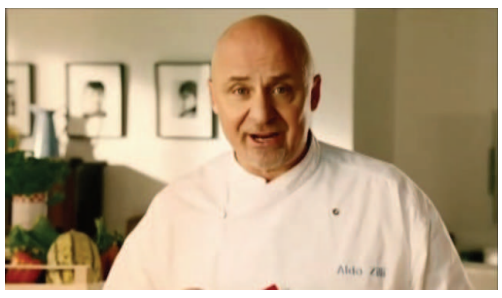

Figure 32. Kellogs Optivita.

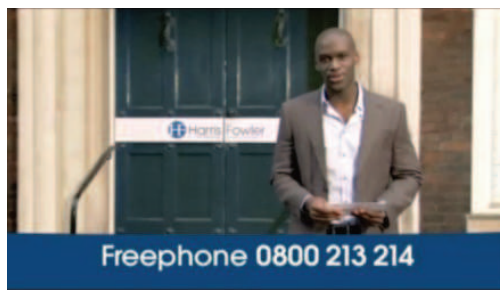

Figure 33. Harris Fowler lawyers. (Colour online.)

The framing of male characters is deployed through medium and long shots, and the use of body parts does not seem to be of particular relevance in their portrayal.

Male voices are used to round up commercials in $60.5 \%$ of the ads, versus $36.8 \%$ in the case of female voices. In general, there is a preference for male voices to endorse products which are either traditionally targeted at men (as in the Priviledge.com car insurance ad, the Wickes Wooden floors ad, or the Ask Jeeves and Norwich Union ads). In contrast, women are still employed as voice overs in ads which deal with healthcare (Social Care ad), beauty products (Sheerblonde ad), and refreshments for women (Ocean Spray Honey Press ad) or in the Maltesers ad, as part of a series of ads which somehow celebrate the right of women to enjoy a lighter moment or "chocolate".

\subsection{Both women and men together in remunerated scenarios}

Women and men depicted together represent $30.5 \%$ of the ads analysed and are depicted in the following more or less stereotypical occupations, where the first part of the couple is male and the second female: ophthalmologist and sales assistant (for example in Lloyds Pharmacy and Optical Express); doctor and nurse (in NSPCC and Fenton Solicitors LLP); and make-up artist and hairdresser (in $L$ 'Oreal Excellence Crème). Female and male characters are represented per- 
forming different tasks as funeral service employees (i.e. Cooperative Funeral Care); shop assistants ( $B \& Q$ ); debt solution company employees (TheDebtPeople); bank clerks (Natwest and Halifax), for example. Female voice-overs are employed more pervasively ( $46.4 \%$ versus $32.1 \%$ for male ones), and more frequently for domestic products ( $81.5 \%$ versus $36.8 \%$ for non-domestic products).

Although the semiotic resource of function ranking shows women and men working, stereotypical occupations can be gleaned from the different activities performed in the ads (for example, make-up artist and hairdresser), or from the different skills attributable to them. Some ads present women visually as "good with doing the talking" and men as more active characters and good with monetary decisions. In the Optical Express ad, the male character is portrayed as the expert in laser eye surgery whereas a female employee does the free consultation with a potential patient (Figures 34-35).
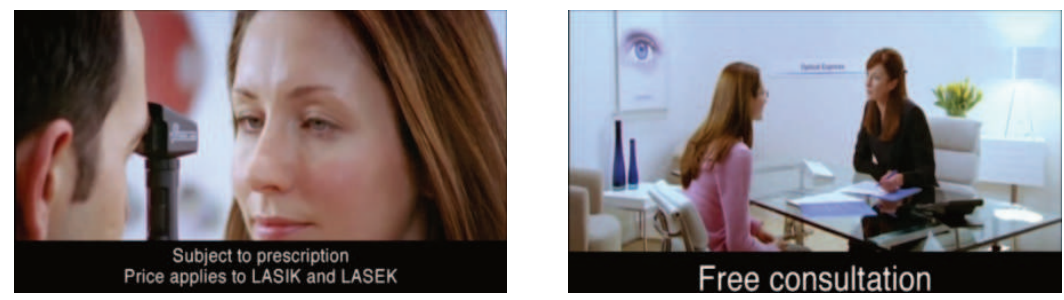

Figures 34-35. Optical Express. (Colour online.)

In the Debt people ad, a male voice over informs the audience of the steps to follow in order to get rid of debts. In step 1, we get a glimpse of a woman answering a call, but we see a male character in step 2 offering specialized free debt advice. It is implied that women will listen to your monetary problems and men will provide a solution for them, as illustrated by Figures 36-37.

In the Lloyds ads, a female health assistant first talks to customers and helps them with prescribed medicines, but it is the male character who will make sure you are getting the best of your medicines in the role of expert. This is evidenced through smiling and interpersonal interaction with the customer in 36 versus a more detached view of the expert in Figure 39.

Offer looks are the common pattern (54\%) although main characters interact with other represented employees of the same and/or different sex in 36\% of the ads (for example in the Sainsbury, NatWest Bank and Asda ads, among others). Demand looks (14\%) can be found in the $A s d a$ ads, where employees talk 

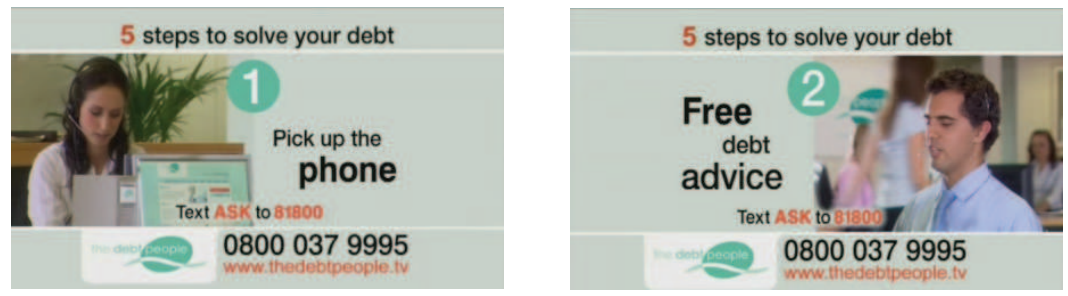

Figures 36-37. The Debt People. (Colour online.)
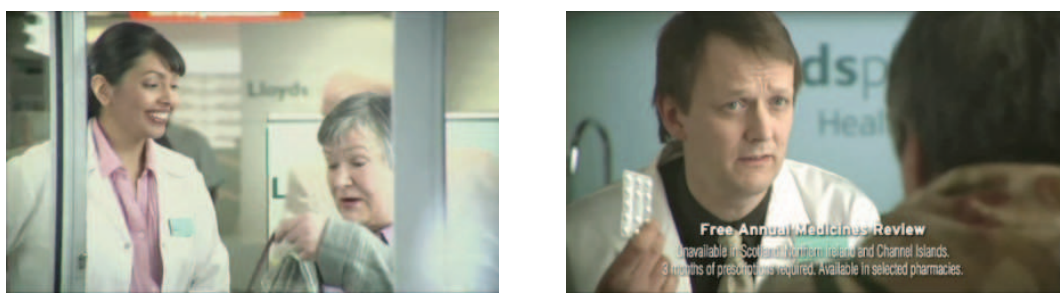

Figures 38-39. Lloyds Pharmacy. (Colour online.)

about sales, in the Aviva one, where potential customers address the audience, and in the $B \& Q$ where shop assistants talk about the importance of kitchens, as the soul of the house, in their role of experts. When the audience is directly addressed, characters are framed very intimately through close-ups, so it is mainly their facial expressions what we get to see to convey intimacy and reliance on the product and the professionals associated with it. However, framing conventions are mainly achieved through medium (29\%) and long shots $(26.5 \%)$, with intimate shots in $15.4 \%$ of the cases.

\section{Conclusions and further discussion}

In this article I have looked at the meaning potential of images in a sample of contemporary British ads. To do so, I have carried out the analysis of some of the dimensions outlined in Goffman's work (1979) and in K\&vL's metafunctions (2006) in an attempt to account for the existence of stereotyped depictions of women and men engaged in remunerated and non-remunerated scenarios, and to evaluate the extent of these depictions. 
One of the most tangible findings is that only $25.3 \%$ of ads in the corpus feature the workplace as the preferred scenario: $60 \%$ for remunerated versus $40 \%$ for non-remunerated settings. This finding backs up previous research by Andren et al. (1978: 120) who concluded that advertising rarely referred to working life and that as a result "work is not part of life". However, even if the workplace is not a preferred scenario for advertisers, its significance should not be underestimated. Not in vain, TV ads are believed to mirror the existing values and traits of a culture and visual depictions can help audiences reflect on the way people organize their society, identify what they value as sacred or simply enjoyable, or what is liked or despised (Kornblum 1994: 28).

The second finding is that stereotyped portrayals are still common in the advertising sample analyzed when it comes to the visual presentation of women and men at work almost four decades after Goffman's study. In general, the quantitative analysis has shown that men primarily work in remunerated scenarios (40.9\%), while women, are more often portrayed in the domain of the home $(48 \%)$, in non-remunerated domestic chores or in parenting tasks. They are, therefore, the ones performing the brunt of housework. In contrast, the fact that men only appear in non-remunerated scenarios in $19 \%$ of the ads helps reinforce the message that men primarily work in remunerated contexts in those TV ads that depict work of any kind and highlights their alienation from domestic chores. Finally, when women and men are portrayed together in an ad, they are slightly more likely to be depicted in non-remunerated settings (35.5\%) than in remunerated ones $(30 \%)$, thus sending off the message that when in the company of women, men are most likely to be involved in parenting activities and dragged out of their professional environment (see the study of Benschop and Meihuizen 2002 for similar results in the representations of men and women in financial annual reports). In remunerated settings, men and women are quite fairly depicted in a similar range of jobs. However, the fact that some ads subtly present women and men in different fields of action, i.e., men solve problems and women do the talking, constitutes another source for stereotyping.

If we turn to the semiotic dimensions being examined à la Goffman and à la K\&vL, it should be stated that most of Goffman's behavior groupings are still at work, and as such, certain categories have been found to be widely used for the reinforcement of stereotyped portrayals (i.e., gaze type, ritualization of subordination, the family and feminine touch), whereas others are either less relevant or do not seem to clearly aid the portrayal of gender stereotypes.

Although one may expect changes in the way women and men are portrayed in media outlets, considering that British society has made considerable pro- 
gress regarding equality in occupational roles, ${ }^{16}$ the findings obtained here do not seem to, either fully reflect the improvement of women's roles in many cultures, or men's progressive participation in domestic chores, especially in the case of non-remunerated scenarios. Despite Pleck's (1987) research, vindicating the role of the involved family man, as one who participates in child care and play activities - the stereotypical depictions of men and women found in this article are highly consistent with those reported by Craig (1992) almost two decades before.

In this respect, women have been found to be stereotypically depicted as mothers in charge of domestic chores in non-remunerated scenarios in which they are framed very intimately, engage with other represented participants (either expert men or their children) through looks, touching and nuzzling activity, while they also smile and offer emotional support. Women are also portrayed as product users in these ads, rather than as experts and female body parts are highly employed in order to focus attention on the activities carried out (cleaning and baby tending) with the result of women being somehow dehumanized as: "[...] Advertisements that show only part of an individual's body indicate that the individual's integrity as a whole person is not important" (Mager and Helgeson 2011).

Men, in contrast, are less frequently depicted in non-remunerated situations and address the audience in the role of product experts passing judgement on the commodity advertised. In this vein, Furnham and Paltzer (2010: 3), in their review of seven comparable studies carried out in Britain from 1989-2008, found a $20 \%-30 \%$ difference between men and women in their roles of user and authority, and concluded that "women remain users, men in the role of experts or authorities". What is more, male characters are hardly portrayed in the company of infants and when portrayed with children (mainly teenagers), men engage in playful activities through long and medium shots, thus revealing a less private interpersonal relationship with their offspring. This last result is also applicable to the depiction of men together with women in non-remunerated scenarios, where family scenes are the norm. These findings tie in well with research carried out by Cantor (1990) on prime-time ads and Tsai and Shumow, (2011) which emphasized the absence of the role of the nurturing father in American advertising.

In remunerated scenarios, male presence almost doubles that of females, which constitutes a striking difference in itself. Even if both women and men are depicted at work, women are still more likely to interact with other repre-

${ }^{16}<$ https://www.gov.uk/government/news/uk-gender-pay-gap $>$. 
sented participants through gaze, especially other women ${ }^{17}$ and more female body parts are also employed ( $37 \%$ versus $5 \%$ for men). Men, in contrast, make a more frequent use of demand looks in their role of experts to lecture or instruct audiences on legal, nutritional or medical issues, whereas women, when addressing the audience directly, do so in traditional female arenas, such as birth control or dieting, and never in the role of experts but as product users. Women also touch other characters or animals and delicately hold products, although framing relies less on close-ups for their presentation than in non-remunerated scenarios. When both women and men are portrayed in a joint remunerated activity, some of the ads seem to still support a hierarchical distribution of roles, placing men in expert roles and women in subordinate ones, or clearly polarizing what women and men do in the ads, in terms of skills, i.e., women are good at talking and men at solving financial problems, or women have a better predisposition to tending to others, whereas men deal with the core of medical issues.

Regarding voice-overs, previous studies have highlighted a constant predominance of male voice-overs in TV ads, with only female presence in those ads mainly purchased by them, such as household, food, and female and care products (cf. Marecek et al. 1978). However, results from this study have shown that women are more frequently employed to present end comments in all the scenarios analyzed, except for ads depicting men in remunerated scenarios. In this respect, findings from previous studies are not upheld in this study (cf. Bartsch et al. 2000) although my findings coincide with those of Furnham and Imadzu (2002), who also found that women were slightly more frequently employed as voice-overs than men $(59.2 \%$ versus $55.9 \%)$.

Although the findings obtained in this study cannot be deemed as conclusive, they are certainly indicative of the fact that gender dichotomies are visually conveyed and reinforced in contemporary advertising, whereas they should have been moderated. This, in turn, has implications for the advertising industry, whose practices lag behind societal changes and norms and aid the propagation of unequal gender representations.

Ultimately, it could also be argued that exposure to such representations in TV ads could be harmful as they can provide guidance for young people's gender roles formation since exposure to media content creates a particular worldview (Gerbner and Gross 1976; Kim and Lowry 2005). Of course, the extent to which such a claim is tenable is an aspect to be tested, since it is audi-

\footnotetext{
${ }^{17}$ Furhnam and Paltzer (2010) also highlight the fact that women tend to be represented in the company of more women than is the case for men.
} 
ences, as active entities, which can interpret, make sense of and decode a TV ad in various ways, which may be or may not be aligned with the advertiser's intended reading or with the researcher's subjective interpretation. Therefore, a further venue for research would certainly have to take into account reader response/reception theory as a way of validating the conclusions drawn from other qualitative studies and thus, as a more reliable way to gain insights into how ads are decoded by audiences and to assess their influence on them.

Last, but not least, the semiotic dimensions which made up the framework of analysis have proven useful for the purpose of the article. However, as advertising strategies and tactics are constantly evolving, it would be interesting to carry out future studies incorporating new dimensions of analysis (for example, Kang's (1997) Body Display). Likewise, it might also be interesting to replicate this study with a wider sample of TV ads - aired both during off-peak and prime time television - in order to test the viability and applicability of Goffman and K\&vL's dimensions as visual carriers of gender stereotyping together with their sensitivity to target audiences.

\section{Acknowledgements}

I would like to thank two anonymous $P S i C L$ reviewers for their valuable comments, which have definitely contributed to an improvement of the final version of this paper.

\section{REFERENCES}

Acevedo, C. R., J. J. Nohara, A. L. Arruda, H. R. S. Tamashiro, and T. Brashear. 2006. "How women are depicted in ads? A content analysis study with Brazilian advertisements". International Business \& Economics Research Journal 5(10). 59-72.

Allan, K. and S. Coltraine. 1996. "Gender displaying television commercials: A comparative study of television commercials in the 1950s and 1980s". Sex Roles 35. 185-203.

Andren, G., L. O. Ericsson, R. Ohlsson and T. Tannsjo. 1978. Rhetoric and ideology in advertising: A content analytical study of American advertising. Stockholm: AB Grafiska Gruppen.

Baker, C. N. 2005. "Images of women's sexuality in advertisements: A content analysis of black- and white-oriented women's and men's magazines". Sex Roles 52. 13-27.

Baldry, A. and P. L. Thibault. 2006. Multimodal transcription and text analysis: A multimedia toolkit and associated on-line coursebook. London and Oakville, CT: Equinox. 
Baldry, A. 2004. "Phase and transition, type and instance: patterns in media texts as seen through a multimodal concordance”. In: O'Halloran, K. (ed.), Multimodal discourse analysis. London and New York: Continuum. 83-108.

Bartsch, R. A., T. Burnett, T. R. Diller and E. Rankin-Williams. 2000. “Gender representation in television commercials: Updating an update". Sex Roles 43. 735-743.

Belkaoui, A. and J. M. Belkaoui 1976. "A comparative analysis of the roles played by women in print advertisements: 1958, 1979, 1972". Journal of Marketing Research 8. 168-172.

Belknap, P. and W. M. Leonard, 1990. “A conceptual replication and extension of Erving Goffman's study of gender advertisements". Sex Roles 25. 103-118.

Bell, P. 2001. Content Analysis of visual images. In: van Leeuwen, T. and C. Jewitt (eds.), Handbook of visual analysis. Sage Publications: London. 10-34.

Bell, P. and M. Milic. 2002. "Goffman's Gender Advertisements revisited: combining content analysis with semiotic analysis”. Visual Communication 1 (2). 203-222.

Benschop, Y., and H. E. Meihuizen. 2002. "Keeping up gendered appearances: representations of gender in financial annual reports". Accounting, Organizations and Society 27(7). 611-636.

Bivins, T. 2016. "Stereotyping in advertising: We are not the people in those pictures". In: M. Duffy and E. Thorson (eds.), Persuasion ethics today. Routledge: New York and London. 65-78.

Bretl, D. J. and J. Cantor. 1998. "The portrayal of men and women in US television commercials: A recent content analysis and trends over 15 years". Sex Roles 18. 595-609.

Brownell, S. and N. Besnier. 2013. "Gender and sexuality”. In: Carrier, J. G. and D. B Gewertz (eds.), The handbook of sociocultural anthropology. London: Bloomsbury. 239-258.

Burgess, D., and E. Burgida.1999. "Who women are, who women should be". Psychology, Public Policy and Law 5(3). 665-692.

Busby, L. J. and G. Leichty. 1993. "Feminism and advertising in traditional and nontraditional women's magazines, 1950s-1980s". Journalism Quarterly 70. 247-264.

Busby, L. J. 1975. "Sex-role research on the mass media". Journal of Communication 25(4). 107-131.

Butler, J. 1990. Gender trouble: Feminism and the subversion of identity. London: Routledge.

Cantor, M. G. 1990. "Prime-time fathers: A study in continuity and change". Critical Studies in Media Communication 7(3). 275-85.

Carli, L. 1990. "Gender, language, and influence". Journal of Personality and Social Psychology 59 (5). 941-951.

Carter, C. and L. Steiner 2004. Critical readings: Media and gender. Maidenhead and New York: Open University Press.

Coltraine, S. and M. Adams. 1997. "Work-family imagery and gender stereotypes: Television and the reproduction of difference". Journal of Vocational Behavior 50(2). 323-347.

Coltrane, S. and M. Messieno. 2000. "The perpetuation of subtle prejudice: Race and gender imagery in 1990s television advertising". Sex Roles 42(5-6). 363-389.

Cook. G. 2001. The discourse of advertising. London and New York: Routledge. 
Courtney, A. E. and T. W. Whipple. 1983. Sex stereotyping in advertising. Lexington, MA: Lexington Books.

Courtney, A. E. and T. W. Whipple. 1974. "Women in TV commercials". Journal of Communication 24. 110-118.

Craig, R. S. 1992. "The effect of television day part on gender portrayals in television commercials: A content analysis". Sex Roles 26. 197-211.

Culley, J. D. and R. Bennett. 1976. "Selling women, selling blacks". Journal of Communication 26(4). 160-174.

DeFleur, M. L. 1964. “Occupational roles as portrayed on television”. Public Opinion Quarterly 28(1). 57-74.

Dietz, T. L. 1998. "An examination of violence and gender role portrayals in video games: Implications for gender socialization and aggressive behavior". Sex Roles 38. 425-442.

Dominick, J. R. and G. E. Rauch. 1972. "The image of women in network TV commercials". Journal of Broadcasting 16. 259-267.

Döring, N. and S. Pöschl. 2016. "Images of men and women in mobile phone advertisements: A content analysis of advertisements for mobile communication systems in selected popular magazines". Sex Roles 55. 173-185.

Dorr, A. 1986. Television and children: A special medium for a special audience. Beverly Hills, CA: Sage.

Downs, A. C and S. K. Harrison. 1985. "Embarrassing age spots or just plain ugly? Physical attractiveness stereotyping as an instrument of sexism on American Television Commercials". Sex Roles 13(1). 9-19.

Eckert, P. and S. McConnell-Ginet, 2003. Language and gender. Cambridge: Cambridge University Press.

Emons, P. A. A., F. Wester, and P. Scheepers. 2010. "'He works outside the home; she drinks coffee and does the dishes': Gender roles in fiction programs on Dutch television”. Journal of Broadcasting \& Electronic Media 51(1). 40-53.

Fairclough, N. 2003. Analysing discourse: Textual analysis for social research. London \& New York: Routledge.

Farris, N. 2014. "The proof is in the pudding: gender specific stereotypes in television advertisements". In: Farris, D. N., M. A. Davis and D. R. Compton (eds.), Illuminating how identities, stereotypes and inequalities matter through gender studies. Netherlands: Springer. 1-81.

Feierabend, S. and W. Klingler. 2011. "Was Kinder sehen: Eine Analyse der Fernsehnutzung Drei-bis 13 jähriger 2010”. Media Perspektiven 4. 169-181.

Ferrante, C., Haynes, A., and S. Kugsley. 1988. "Image of women in television advertising”. Journal of Broadcasting \& Electronic Media 32. 231-237.

Frith, K. T., Cheng, H., and P. Shaw. 2004. "Race and beauty: A comparison of Asian and Western models in women's magazine advertisements". Sex Roles 50. 53-61.

Furnham, A. and T. Mak. 1999. "Sex role stereotyping in TV commercials: A review and comparisons of 14 studies done on five continents over 25 years". Sex Roles 40. 413-431.

Furnham, A. and E. Imadzu. 2002. "Gender portrayal in British and Japanese TV advertisements". Communications 27. 319-348. 
Furnham, A. and S. Paltzer. 2010. "The portrayal of men and women in television advertisements: An updated review of 30 studies published since 2000”. Scandinavian Journal of Psychology 51. 216-236.

Ganahl, D., K. Kim and S. B. Netzley. 2003. "Longitudinal analysis of network commercials: How advertisers portray gender". Media Report to Women 31. 11-15.

Gauntlett, D. 2002. Media, gender and identity: An introduction. London: Routledge.

Geis, F. L., V. Brown, J. Jennings and N. Porter. 1984. "TV commercials as achievement scripts for women". Sex Roles 10(7). 513-525.

Gerbner, G. and L. Gross. 1976. "Living with television: The violence profile”. Journal of Communication 26(2). 172-194.

Glascock, J. 2001. "Gender roles on prime-time network television: Demographics and behaviours". Journal of Broadcasting \& Electronic Media 45(4). 656-669.

Goffman, E. 1979. Gender advertisements. New York: Harper \& Bow.

Grossman, A. H., A. R. D'Augelli, T. J. Howell and S. Hubbard. 2006. "Parents' reactions to transgender youths' gender nonconforming expression and identity". Journal of Gay \& Lesbian Social Services 18(1).3-16.

Halliday, M. A. K. 2004. An introduction to Functional Grammar. London: Arnold.

Hall, E. T. 1966. The hidden dimension. New York: Doubleday \& Co.

Heilman, M. E. 1983. "Sex bias in work settings: The lack of fit model". Research in Organization Behavior 5. 269-298.

Heilman, M. E. 1995. "Sex stereotypes and their effects in the workplace: What we know and what we don't know". Journal of Social Behavior and Personality 10. 3 26.

Heilman, M. E. 2001. "Description and prescription: How gender stereotypes prevent women's ascent up the organizational ladder". Journal of Social Issues 57. 657 674.

Hyland, K. 2009. Teaching and researching writing. Harlow: Pearson.

Iedema, R. 2001. "Resemioticization". Semiotica 137(1/4). 23-39.

Iedema, R. 2003. "Multimodality, Resemioticization: Extending the analysis of discourse as a multisemiotic practice". Visual Communication 2(1). 29-57.

Jewitt, C. and R. Oyama. 2001. "Visual meaning: A social semiotic approach". In: van Leeuwen, T. and C. Jewitt (eds.), Handbook of visual analysis. London: Sage. 134 156.

Jhally, S. 2014. The codes of advertising: Fetishism and the political economy of meaning in the consumer society. London: Routledge.

Kalisch, P. A. and B. J. Kalisch. 1984. "Sex-role stereotyping of nurses and physicians on prime-time television: A dichotomy of occupational portrayals". Sex Roles 10. 533-553.

Kang, M.-E. 1997. "The portrayal of women's images in magazine advertisements: Goffman's gender analysis revisited". Sex Roles 37(11). 979-996.

Kilbourne, J. 1999. Deadly Persuasion: Why women and girls must fight the addictive power of advertising. New York, NY: The Free Press.

Kim, K. and D. Lowry. 2005. "Television commercials as a Lagging Social Indicator: Gender role stereotypes in Korean television advertising”. Sex Roles 53(11/12). 901-910. 
Klassen, M. L., C. R. Jasper and A. M. Schwartz. 1993. "Men and women: Images of their relationships in magazine advertisements". Journal of Advertising Research 33. 30-39.

Knoll, S., M. Eisend and J. Steinhagen. 2011. "Gender roles in advertising”. International Journal of Advertising 30. 867-888.

Kornblum, W. 1994. Sociology in a changing society. Fort Worth, TX: Harcourt Brace.

Kunkel, D., B. L. Wilcox, J. Cantor, P. Dowrick, S. Linn and E. Palmer. 2004. "Psychological issues in the increasing commercialization of childhood". Report of the APA Task Force on Advertising and Children. American Psychological Association. Washington DC. 20-54.

Kress, G. and T. van Leeuwen. 1996. Reading images: The grammar of visual design. London: Routledge.

Kress, G. and T. van Leeuwen. 2006. Reading images: The grammar of visual design. (2nd ed.) London: Routledge.

Leech, G. N. 1966. English in advertising: A linguistic study of advertising in Great Britain. London: Longman.

Leitner, G. 2001. "The sociolinguistics of communication media". In: Coulmas, F. (ed.), The handbook of sociolinguistics. Malden, MA: Blackwell. 187-204.

Lindner, K. 2004. "Images of women in general interest and fashion advertisements from 1955 to 2002". Sex Roles 51. 409-421.

Lovdal, L. T. 1989. "Sex role messages in television commercials: An update". Sex Roles 21(11/12). 715-724.

Machin, D. 2007. Introduction to Multimodal Analysis. London. Arnold.

Machin, D. 2010. Analyzing popular music: Image, sound and text. London: Sage.

Machin, D. and A. Mayr. 2012. How to do Critical Discourse Analysis: A multimodal introduction. London: Sage.

Mager, J. and J. G. Helgeson. 2011. "Fifty years of advertising images: Some changing perspectives on role portrayals along with enduring consistencies". Sex Roles 64. $238-252$.

Marecek, J., J. A. Piliavin, E. Fitzsimmons, E.C. Krogh, E. Leader and B. Trudell. 1978. "Women as T. V. experts: The voice of authority?". Journal of Communication 28(1). 159-168.

McArthur, L. Z. and B. G. Resko 1975. "The portrayals of men and women in American television advertisements". Journal of Social Psychology 97. 209-220.

McKay, N. J. and V. Covell. 1997. "The impact of women in advertisements on attitudes towards women". Sex Roles 36 (9). 573-583.

McNeil, J. 1975. "Feminism, femininity and the television shows: A content analysis". Journal of Broadcasting 19. 259-269.

Milner, L., and J. M. Collins. 2000. "Sex-role portrayals and the gender of nations". Journal of Advertising 29. 67-79.

Milner, L. and B. Higgs. 2004. "Gender sex role portrayals in international television advertising over time: The Australian experience". Journal of Current Issues and Research in Advertising 26. 81-95.

Nassif, A. and B. Gunther. 2008. "Gender representation in television advertisements in Britain and Saudi Arabia". Sex Roles 58(11). 752-760. 
O’Donell, W. J. and K. J. O’Donell. 1978. “Update: Sex-role messages in TV commercials". Journal of Communication 28(1). 156-158.

O'Halloran, K. 2004. (ed.). Multimodal Discourse Analysis. London and New York: Continuum.

Paek, H. J., M. R. Nelson and A. M. Vilela. 2010. "Examination of gender-role portrayals in television advertising across seven countries". Sex Roles 64(3). 192-207.

Parson, T. and R. F Bales. 1995. Family, socialization and interaction process. Glencoe, IL: Free Press.

Patterson, C. E. and M. K. Hogg. 2004. "Gender identity, gender salience and symbolic consumption”. In: Scott, L. and C. Thompson (eds.), Gender and Consumer Behavior, vol. 7. Madison, WI: Association for Consumer Research.

Pennock-Speck, B. and M. M. Del Saz-Rubio. 2013. "A multimodal analysis of facework strategies in a corpus of charity ads on British Television." Journal of Pragmatics 49(1). 38-56.

Pennock-Speck, B. and M. M. Del Saz-Rubio. 2013. (eds.) The Multimodal Analysis of television commercials. Universitat de Valéncia Publications.

Pennock-Speck, B. and M. Fuster-Marquez. 2014. "Imperatives in voice-overs in British commercials: 'Get this, buy that, taste the other'". Discourse and Communication 8(4). 411-426.

Plakoyiannaki, E., and Y. Zotos. 2009. "Female role stereotypes in print advertising: Identifying associations with magazine and product categories". European Journal of Marketing 43. 1411-1434.

Pleck. J. H. 1987. “American fathering in historical perspective”. In: Kimmel, M. (ed.), Changing men: New directions in research on men and masculinity. Newbury Park, CA: Sage. 83-97.

Renkema, J. 2004. Introduction to discourse studies. Amsterdam: John Benjamins Publishing Company.

Rocha-Rodrigues, F. 2016. Deconstruction of the gender binary in advertising: an interpretive analysis and discussion. Retrieved from:

$<$ https://www.academia.edu/29974007/Deconstruction_of_the_gender_binary_in_ advertising_an_interpretive_analysis_and_discussion>.

Royce, T. 1998. Visual-verbal intersemiotic complementarity in The Economist Magazine. (PhD dissertation, University of Reading, United Kingdom.)

Royce, T. 2007. "Intersemiotic complementarity: A framework for Multimodal Discourse Analysis". In: Royce, T. and W. Bowcher (eds.), New directions in the analysis of multimodal discourse. Mahwah, NJ/London: Lawrence Erlbaum Associates. 63-109.

Rudy, R. M., L. Popova and D. G. Linz. 2010a. "The context of current content analysis of gender roles: An introduction to a special issue". Sex Roles 62. 705-720.

Rudy, R. M., L. Popova and D. G. Linz. 2010b. "Content analysis. Special issue". Sex Roles 62. 705-847.

Shrikhande. V. 2003. Stereotyping women in television advertisements. (MA thesis, University of Louisiana.)

Signorelli, N. and M. Leavs. 1992. "Children, television and conceptions about chores, attitudes, and behaviours". Sex Roles 27. 337-56. 
Signorelli, N., D. McLeod and E. Healy. 1994. "Gender stereotypes in MTV commercials: The beat goes on". Journal of Broadcasting and Electronic Media 38. 91101.

Sirakaya, E. and S. Sönmez. 2000. "Gender images in state tourism brochures: An overlooked area in socially responsible tourism marketing". Journal of Travel Research 38(4). 353-362.

Subrahmanyam, K and D. Smahel. 2011 "Constructing identity online: Identity Exploration and Self-Presentation”. Digital Youth, Advancing Responsible Adolescent Development 4. 59-80.

Taylor, S. E., L.A. Pepalau and D. O. Sears. 2003. Social psychology. (11th ed.) New Jersey: Pearson Education.

Thibault, P. J. 2000. "The multimodal transcription of a television advertisement: Theory and practice". In: Baldry, A. (ed.), Multimodality and multimediality in the distance learning age. Campobasso: Palladino. 311-385.

Tsai, W. H. S. and M. Shumow. 2011. "Representing fatherhood and male domesticity in American advertising". Interdisciplinary Journal of Research in Business 1(8). $38-48$.

Tsichla, E., and Y. C. Zotos. 2013. "Gender stereotypes in Cypriot magazine advertisements: A comparison of single and relationship portrayals". Paper presented at the 18th International Conference on Corporate and Marketing Communication, April 11-12, Salerno, Italy.

Tuchman, G. 1978. "Introduction: The symbolic annihilation of women by the mass media". In: Tuchman, G., A. Kaplan Daniels and J. Bennet (eds.), Hearth and home: Images of women and the media. New York: Oxford University Press. 3-38.

Twardowska, A. and E. Olczyk. 2003. "Kobiety w mediach" [Women in themedia]. In: Olczyk, A., and A. Twardowska (eds.), Kobiety w Polsce [Women in Poland]. Warsaw: Centrum Praw Kobiet. 260-283.

Umiker-Sebeok, J. 1996. "Power and construction of gendered spaces". International Review of Sociology 6. 389-404.

Valls-Fernández, F. and J. M. Martinez-Vincente. 2007. “Gender stereotypes in Spanish television commercials". Sex Roles 56. 691-699.

Van Leeuwen, T. 2004. "Ten reasons why linguistics should pay attention to visual communication.” In: Levine, P. and R. Scollon (eds.), Discourse and technology: Multimodal Discourse Analysis. Washington: Georgetown University Press. 7-19.

Van Leeuwen, T. 2008. Discourse and practice: New tools for critical discourse analysis. New York: Oxford University Press.

Vande Berg, L. R. and D. Streckfuss. 1992. "Prime-time television's portrayal of women and the world of work: A demographic profile". Journal of Broadcasting \& Electronic Media 36(2). 195-298.

Wodak, R. 2001. Methods of Critical Discourse Analysis. London: Sage.

Wodak, R. and G. Weiss. 2003. "Introduction: Theory, interdisciplinarity and Critical Discourse Analysis". In: Weiss, G. and R. Wodak (eds.), Critical Discourse Analysis. Theory and interdisciplinarity. London: Palgrave Macmillan. 1-34.

Yang, F. and C. Li. 2016. "The congruity effect of topic, colour, and gender on health messages' persuasiveness in cyberspace”. Computers in Human Behaviour 64. 299 307. 
Zarghooni, S. 2007. A study of self-presentation in light of facebook. (MA thesis, University of Oslo.)

\section{Address correspondence to:}

Milagros del Saz Rubio

Department of Applied Linguistics

Universitat Politècnica de València

$\mathrm{C} /$ Vera $\mathrm{s} / \mathrm{n}$

46022 Valencia

Spain

masaru@idm.upv.es 